\title{
Morphology, surface topography and optical studies on electron beam evaporated MgO thin films
}

\author{
A CHOWDHURY* and J KUMAR \\ Materials Science Programme, Indian Institute of Technology, Kanpur 208 016, India
}

MS received 16 November 2005; revised 24 August 2006

\begin{abstract}
Electron beam evaporated thin films of $\mathrm{MgO}$ powder synthesized by burning of magnesium ribbon in air and sol-gel technique are studied for their microstructure (SEM), surface topography (AFM), and optical transmission behaviour (UV-visible spectroscopy). MgO thin films are shown to be either continuous or have mesh like morphology. The bar regions are believed to be of magnesium hydroxide formed due to absorption of moisture. Their AFM images exhibit columnar/pyramidal/truncated cone structure, providing support to the 3D Stranski-Krastanov model for film growth. Further, they are shown to have high transmittance $(\sim 90 \%)$ in the wavelength range $400-600 \mathrm{~nm}$, but absorb radiation below $350 \mathrm{~nm}$ substantially giving signature of a band transition.
\end{abstract}

Keywords. Thin film; surface morphology; magnesium oxide.

\section{Introduction}

Magnesium oxide $(\mathrm{MgO})$ thin films find several applications in the different developing areas of materials science and engineering. Its thin films find application as protective layer (Boeuf 2003) for plasma display panels (PDPs), an alternative dielectric to silicon dioxide $\left(\mathrm{SiO}_{2}\right)$, and dynode in electron multipliers in Zeus display panel, reflecting and antireflecting coatings (Chowdhury 2005). $\mathrm{MgO} / \mathrm{TiO}_{x}$ superlattices (Imai et al 1992) have been synthesized on an $\mathrm{MgO}$ substrate for the combination of various thicknesses of titanium oxide layers and $\mathrm{MgO}$ layers. $\mathrm{MgO}$ single crystal is an excellent substrate for preparing ferroelectric and superconductor thin films (Phillipsa Julia 1996).

There are several methods by which $\mathrm{MgO}$ thin films have been prepared in the past. One popular choice is to use the pulsed laser deposition technique for $\mathrm{MgO}$ layers on GaAs (Nashimoto et al 1992). They found the best crystallographic quality at $350^{\circ} \mathrm{C}$ in $5 \times 10^{-6}$ Torr $\mathrm{O}_{2}$. Polycrystalline $\mathrm{MgO}$ films (Boo et al 1996) have been prepared on GaAs (100) substrates by low-pressure metal-organic chemical vapour deposition using $\mathrm{Mg}$ (2,2,6,6-tetramethyl-3,5-heptanedionate $)_{2}$ as a precursor and oxygen as a carrier gas. The major orientation has been found out to be in the [100] direction at the substrate temperature of $300^{\circ} \mathrm{C}$. $\mathrm{MgO}$ thin films have been deposited on $\mathrm{Si}(111)$ substrates by atomic layer growth (ALG) using a hydrolysis surface reaction of $\mathrm{Mg}\left(\mathrm{C}_{2} \mathrm{H}_{5}\right)_{2}$ and $\mathrm{H}_{2} \mathrm{O}$ (Huang and Kitai Adrian 1992). Park et al (2000) studied

\footnotetext{
*Author for correspondence (preac@leeds.ac.uk)
}

surface-discharge characteristics of $\mathrm{MgO}$ thin films prepared by reactive RF unbalanced magnetron sputtering. Sol-gel synthesis of crystalline magnesium oxide (Chakrabarti et al 2002, 2003) has been reported on soda lime glass using non-alkoxide precursor chemicals for the first time. But they could not avoid the formation of magnesium hydroxide in their final films along with the presence of periclase and $\beta-\mathrm{MgO}$ phase. Ho et al (1997) prepared $\mathrm{MgO}$ thin films with either (111) or (200) preferential orientation on (100) Si substrates by sol-gel method followed by heat treatment at $800^{\circ} \mathrm{C}$. But in almost all the application fields there is a common problem associated with it, i.e. the problem of hydration. Studies in the past (Kim et al 1994) suggest that during synthesis of $\mathrm{MgO}$ thin films aqueous/chemical (e.g. spin coating) route should be avoided. But still evidence of hydration has been noted also, which in turn deteriorates other properties, viz. optical, electronic etc. Here we report synthesis of magnesium oxide thin films by e-beam evaporation method with two different powders, viz. $\mathrm{MgO}$ powder obtained by burning of magnesium ribbon in air and powder obtained through sol-gel technique. Thin films have been subsequently prepared by electron beam evaporation method using the synthesized $\mathrm{MgO}$ powder and studied for their microstructure (SEM), surface topography (AFM), and optical transmission behaviour (UV-visible spectroscopy). Effect of annealing on the properties of thin films has also been investigated.

\section{Experimental}

Mostly, $\mathrm{MgO}$ thin films are extensively applied as protective layer for plasma display panels (PDPs) where thin $\mathrm{MgO}$ 
Table 1. List of raw materials used for the synthesis of $\mathrm{MgO}$.

\begin{tabular}{|c|c|}
\hline Materials & Specification \\
\hline $\begin{array}{l}\text { Magnesium acetate tetrahydrate } \\
{\left[\left(\mathrm{CH}_{3} \mathrm{COO}\right)_{2} \mathrm{Mg} \cdot 4 \mathrm{H}_{2} \mathrm{O}\right]}\end{array}$ & Chloride, $0.005 \%$; sulphate, $0.01 \%$; lead, $0.002 \%$ \\
\hline Magnesium ribbon $(\mathrm{Mg})$ & Lead, $0.01 \%$; copper, $0.005 \%$; iron, $0.05 \%$; substances insoluble in $\mathrm{HCl}, 0.05 \%$ \\
\hline Ethyl alcohol $\left(\mathrm{C}_{2} \mathrm{H}_{5} \mathrm{OH}\right)$ & $\begin{array}{l}\text { Water, } 0.1 \% \mathrm{v} / \mathrm{v} \text {; acidity, } 0.01 \mathrm{mln} \% \text {; non-volatile matter, } 0.001 \% \text {; aldehydes } \\
\text { and ketones, } 0.005 \% \text {; furfuraldehyde, } 0.001 \%\end{array}$ \\
\hline Oxalic acid $\left[(\mathrm{COOH})_{2} \cdot 2 \mathrm{H}_{2} \mathrm{O}\right]$ & Min. assay $=99 \cdot 08 \%$ \\
\hline
\end{tabular}

Table 2. Sample code for $\mathrm{MgO}$ thin films.

\begin{tabular}{lllr}
\hline Sl. no. & $\begin{array}{c}\text { Pellet used as source material for } \\
\text { electron beam evaporation }\end{array}$ & Annealing conditions & Sample code \\
\hline 1. & $\begin{array}{c}\text { Pellet of } \mathrm{MgO} \text { powders obtained by } \\
\text { burning magnesium ribbon }\end{array}$ & $\begin{array}{c}\text { Annealed at } 500^{\circ} \mathrm{C} \text { in presence of oxygen with a } \\
\text { flow rate of } 30 \mathrm{cc} / \mathrm{s}\end{array}$ & $\mathrm{A}$ \\
& & Annealed at $500^{\circ} \mathrm{C}$ in presence of air & $\mathrm{B}$ \\
2. & & Nil & $\mathrm{C}$ \\
3. & $\mathrm{MgO}$ powders obtained by sol-gel method & Annealed at $500^{\circ} \mathrm{C}$ in presence of oxygen & $\mathrm{D}$ \\
4. & & with a flow rate of $30 \mathrm{cc} / \mathrm{s}$ & $\mathrm{E}$ \\
5. & Annealed at $500^{\circ} \mathrm{C}$ in presence of air & $\mathrm{F}$ \\
6. & & Nil & \\
\hline
\end{tabular}

films are coated on glass substrates and hence glass substrates have been chosen for experimental purpose. The glass slides of size $25 \times 25 \times 1.3 \mathrm{~mm}$ were used as substrate. They were first cleaned with soap detergent as a routine cleaning for dirt, boiled in $1: 2$ chromic acid solutions for sometime for alkali/acid removal, and rinsed in distilled water. Subsequently, the slides were dipped in acetone, subjected to an ultrasonic cleaning to ensure a dirt and dust free slide, and dried by an electric air blower. Finally, the slides were wiped with lint free tissue paper and transferred to a dust free chamber.

First, pellets of $10 \mathrm{~mm}$ diameter were made from $\mathrm{MgO}$ powder obtained by burning of magnesium ribbon in air and sol-gel technique using a cold press at 4 ton and then sintered at $1000^{\circ} \mathrm{C}$ for $14 \mathrm{~h}$. Magnesium acetate tetrahydrate $\left[\left(\mathrm{CH}_{3} \mathrm{COO}\right)_{2} \mathrm{Mg} \cdot 4 \mathrm{H}_{2} \mathrm{O}\right]$ from E. Merck (India) Ltd., ethyl alcohol $\left(\mathrm{C}_{2} \mathrm{H}_{5} \mathrm{OH}\right)$ from Hayman Ltd., Essex and oxalic acid $\left[(\mathrm{COOH})_{2} \cdot 2 \mathrm{H}_{2} \mathrm{O}\right]$ from Ranbaxy Laboratories Ltd. are used as the raw materials for synthesis of sol-gel $\mathrm{MgO}$ and magnesium ribbon from Loba Chemical Ltd., India was used for combustion method. Chemical specifications of the raw materials are given in table 1 .

A HHV vacuum coating unit model 12A4D-SC equipped with a $6 \mathrm{kV}$ electron beam gun was employed to make magnesium oxide films at a pressure of $\sim 10^{-5}$ torr. The emission current in the range $60-80 \mathrm{~mA}$ was found to be suitable for the evaporation of magnesium oxide from the pellet put in a copper hearth. The deposition time was kept constant for all the films. The deposition rate is dependent on the electron beam voltage and emission current, which was again, kept constant for all the films. Thin films were prepared by maintaining substrates at a fixed distance and varying the time (up to $15 \mathrm{~min}$ maximum) of deposition. The thin films were then taken out of the bell jar and stored in a vacuum desiccator. Annealing of thin films was done at $500^{\circ} \mathrm{C}$ in air or oxygen ambient as per details given in table 2 with respective sample codes.

Various techniques employed for characterization of $\mathrm{MgO}$ thin films included scanning electron microscopy (SEM), atomic force microscopy (AFM) and ultraviolet visible spectroscopy. Thickness of $\mathrm{MgO}$ thin films was determined by Alpha-Step 500 Profiler. For observing the microscopic nature of the thin films, a scanning electron microscope (SEM) model FEI Quanta 200 was used in the secondary electron mode. Surface roughness of thin films was examined in an atomic force microscope of Molecular Imaging, USA, in acoustic a.c. mode at a scan rate $1.5-2.2$ lines/s in air at room temperature. Its cantilever was NSC 12 (C) from MikroMasch with force constant of $4.5 \mathrm{~N} / \mathrm{m}$ at a frequency of $160 \mathrm{KHz}$. Optical percentage transmittance $(T)$ and absorbance $(A)$ of magnesium oxide thin films were measured in the wavelength range 200$800 \mathrm{~nm}$ with a UV/vis spectrometer, Perkin Elmer, model Lambda 40.

\section{Results and discussion}

Figure 1 shows the morphology of thin films prepared by e-beam evaporation of $\mathrm{MgO}$ powder synthesized by combustion of magnesium ribbon (group C) and sol-gel process (group F) as observed in SEM in SE mode. While the films of group C are quite thick (2927 $\AA$ ) displaying large line roughness and cross linking morphology (figures 1 (a)-(d)), those with group F (429 A) are thin, very smooth 

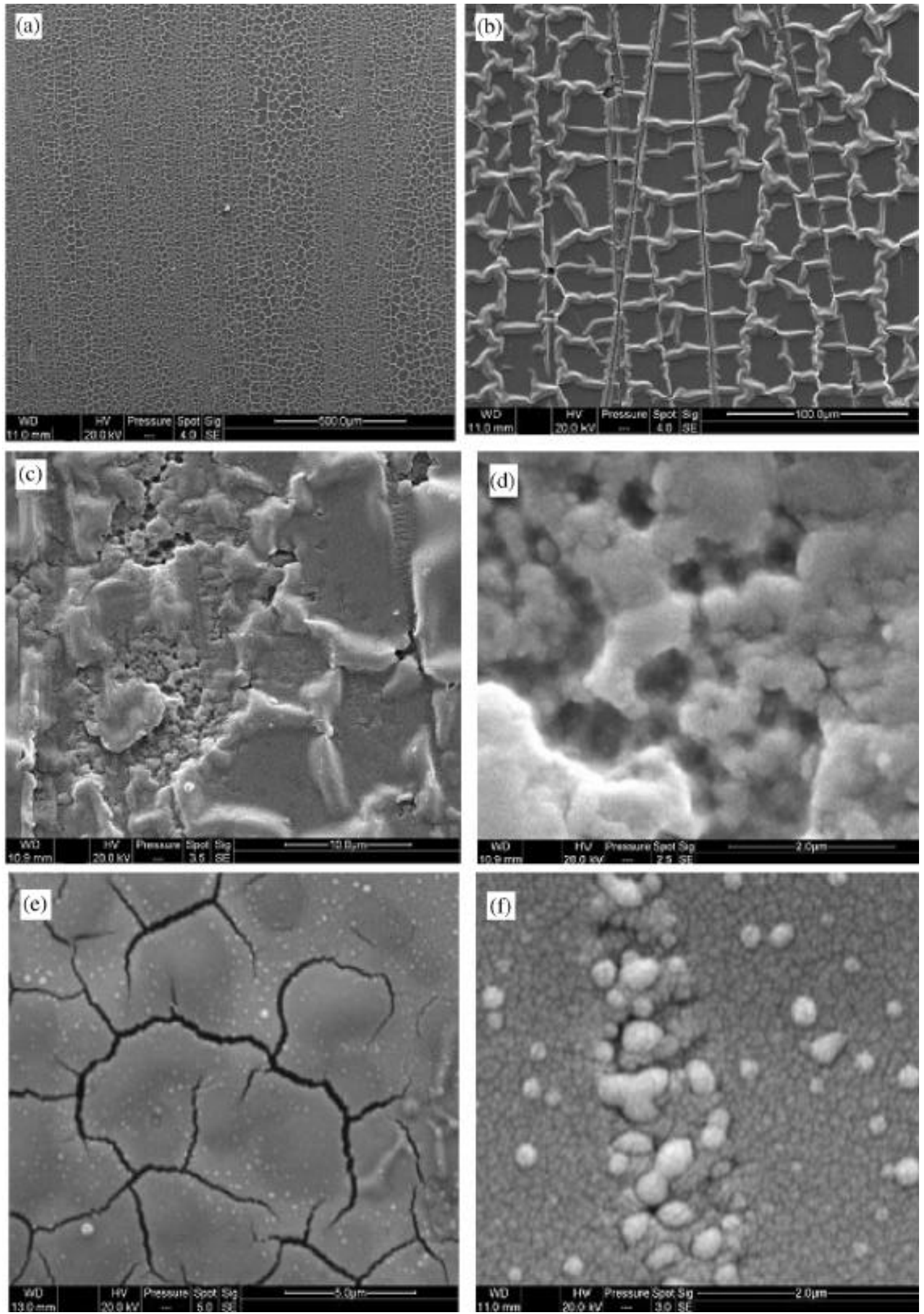

Figure 1. Scanning electron micrographs of $\mathrm{MgO}$ thin films prepared by e-beam evaporation from powder synthesized (a)-(d) by combustion of magnesium ribbon as prepared [group C] and (e)-(f) by sol-gel process as prepared [group F]. 

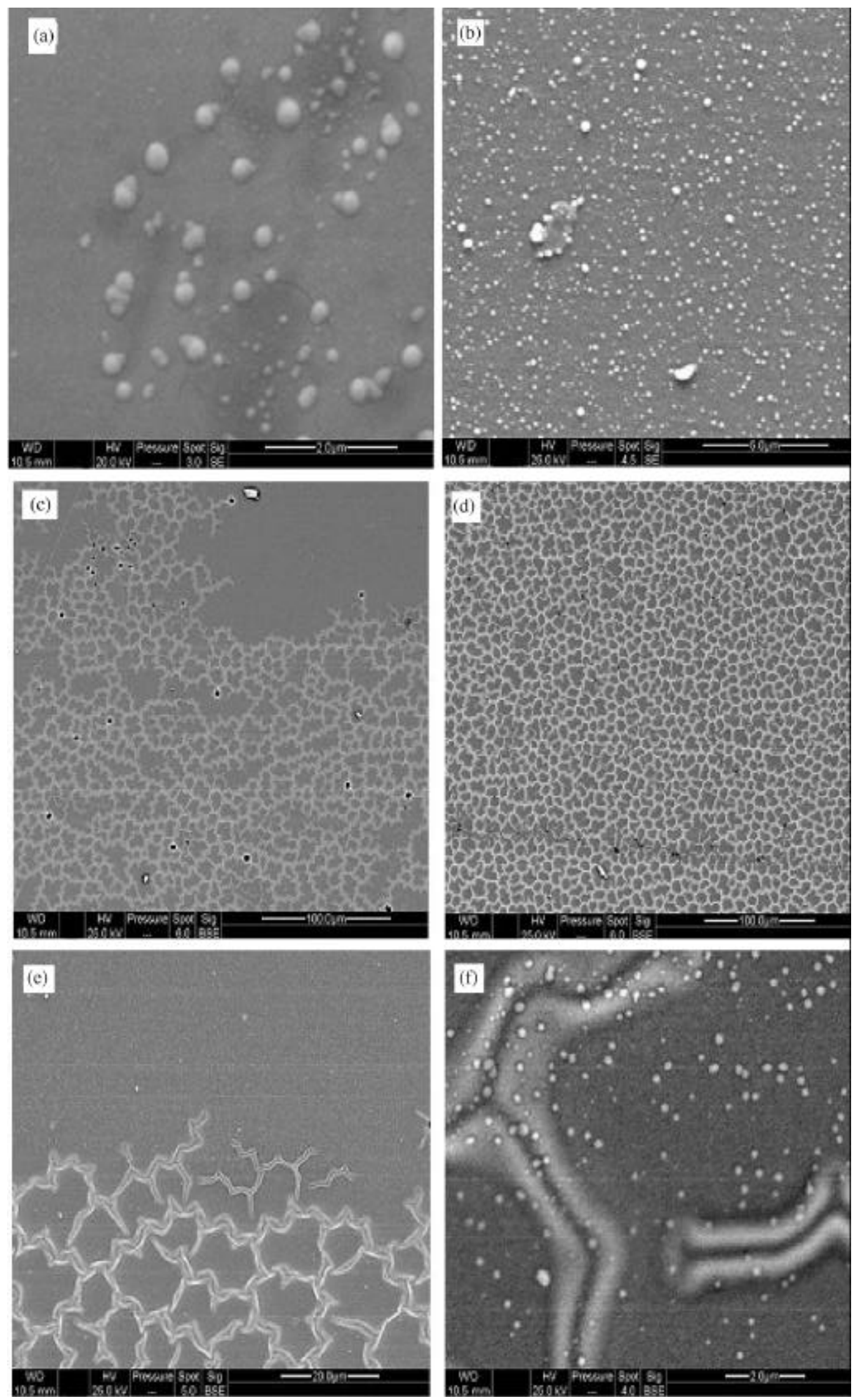

Figure 2. Scanning electron micrographs of $\mathrm{MgO}$ thin films prepared by e-beam evaporation from powder synthesized (b)-(f) by sol-gel process after annealing at $550^{\circ} \mathrm{C}$ in oxygen [group D] and (a) by combustion of magnesium ribbon after annealing at $550^{\circ} \mathrm{C}$ in air [group B]. 
with grain-like structure and zigzag discontinuities/cracks at places (like boundaries) (figures 1(e), (f)). The films produced with $\mathrm{MgO}$ powder obtained by sol-gel process on annealing at $500^{\circ} \mathrm{C}$ in oxygen (group D), became nearly continuous and show distribution of spherical shape particles (figure 2(b)). After annealing in air at $500^{\circ} \mathrm{C}$, e-beam evaporated thin films of $\mathrm{MgO}$ powder synthesized by combustion of magnesium ribbon (group B) exhibit morphology as shown in figure 2(a). SEM observation indicates presence of thick and prominent chain-like boundary regions all over as in group $\mathrm{C}$ thin films obtained by $\mathrm{MgO}$ powder synthesized by combustion of magnesium ribbon without annealing (figures 1(a), (b)).

At other places, microstructure has chain-like regions but not necessarily distributed, e.g. (figures 2(c)-(f)). This suggests that boundary-like regions may possibly arise due to formation of a different compound, such as magne- sium hydroxide $\left[\mathrm{Mg}(\mathrm{OH})_{2}\right]$ as $\mathrm{MgO}$ has a tendency to absorb water very quickly. In a polycrystalline material, grain boundaries are considered as the disordered regions and hence more reactive. It is believed that the formation of magnesium hydroxide occurs in such regions and grows further to cover up the whole film like a zigzag mesh (depicting a self assembled pattern) (figure 1(b)). Boundary-like regions being thick show the mesh structure prominently and has large line roughness as well whereas the mesh in group D film is much finer (figure 2(d)). The details of $\mathrm{MgO}$ films not depicting chain-like structure with poor contrast in SEM are observed under AFM. The atomic rearrangement processes in thin films are mainly guided by four basic phenomena: (a) shadowing, (b) surface diffusion, (c) bulk diffusion and (d) desorption (Milton 2001). The last three are quite common, while shadowing actually occurs in special situations and de-
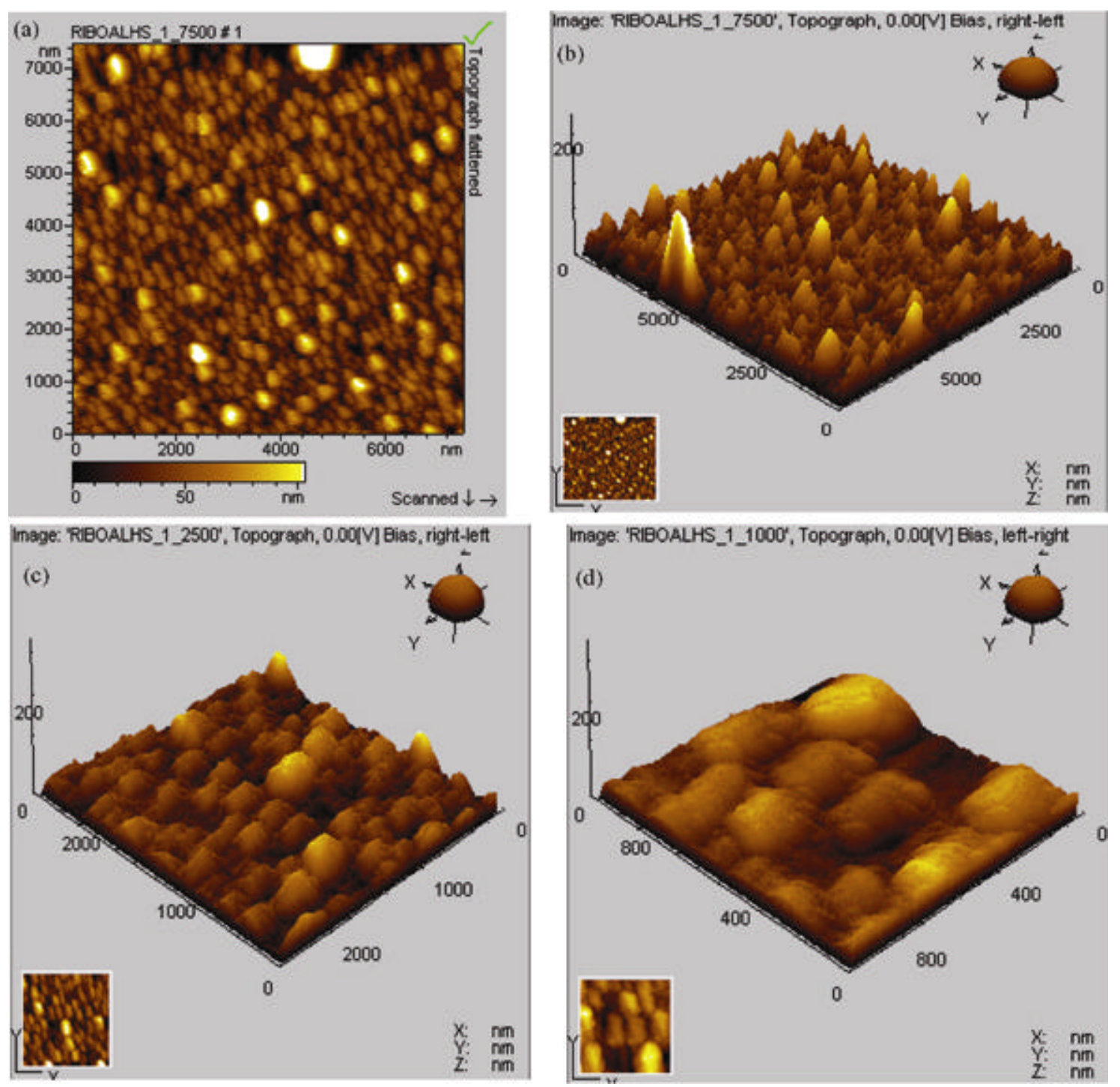

Figure 3. AFM images of e-beam evaporated $\mathrm{MgO}$ thin films synthesized by pellet of $\mathrm{MgO}$ powders obtained by burning magnesium ribbon and annealed at $500^{\circ} \mathrm{C}$ in oxygen (group A). 

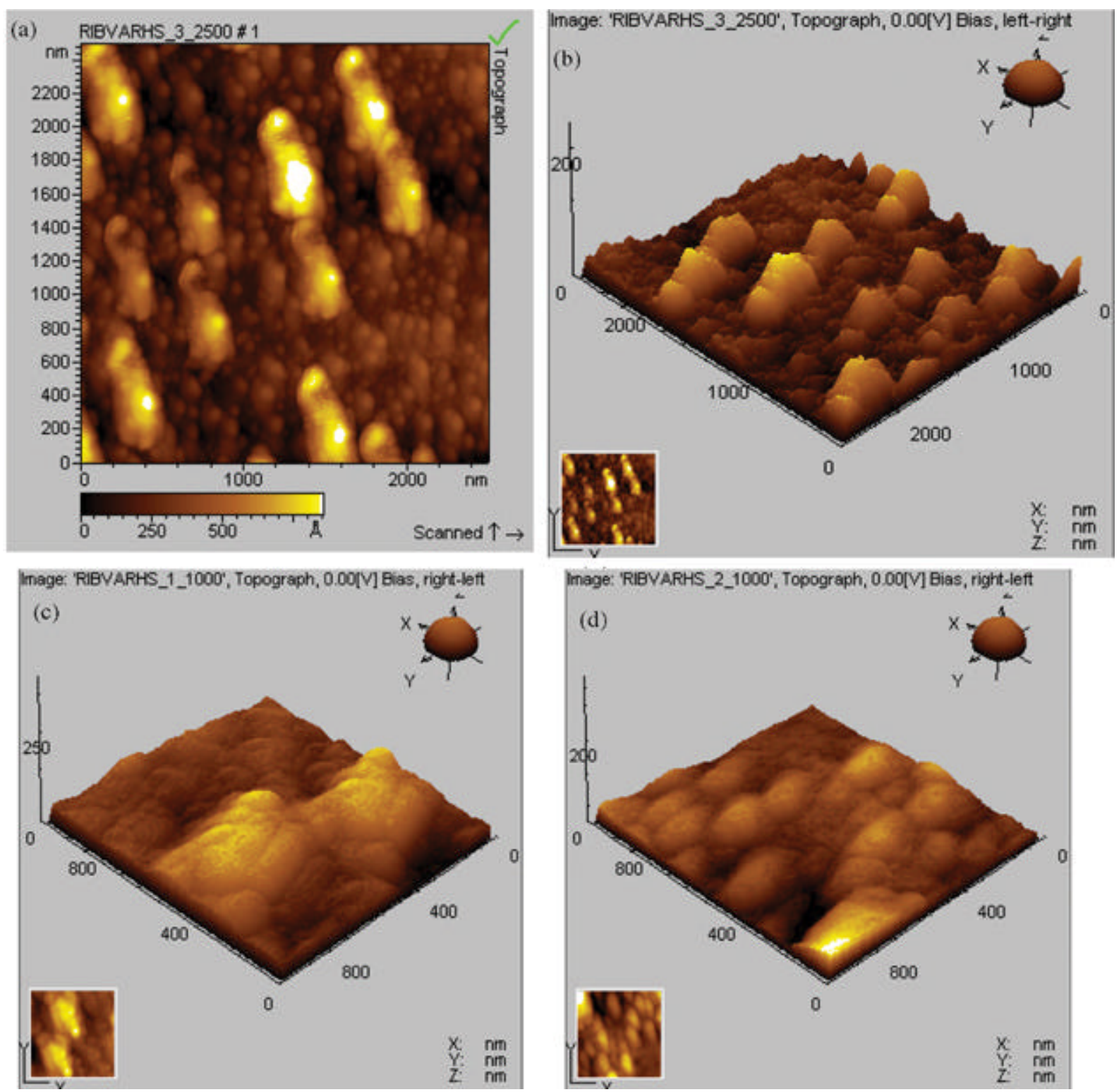

Figure 4. AFM images of e-beam evaporated $\mathrm{MgO}$ thin films synthesized by pellet of $\mathrm{MgO}$ powders obtained by burning magnesium ribbon and annealed at $500^{\circ} \mathrm{C}$ in air (group B). The images are taken at three different regions $(\mathbf{a} / \mathbf{b}, \mathbf{c}, \mathbf{d})$.

pends on the geometric constraint imposed by the roughness of the growing film and the line of sight impingement of the arriving atoms. In this work, AFM observation studies have been made of the e-beam evaporated thin films synthesized by $\mathrm{MgO}$ powder obtained by burning magnesium ribbon and sol-gel process to understand the nature of film growth.

Figure 3 shows AFM images of group A thin film synthesized by $\mathrm{MgO}$ powders obtained by combustion of magnesium ribbon after annealing at $500^{\circ} \mathrm{C}$ in oxygen. These clearly show (figures 3(b)-(c)) faceted columnar microstructure of varied height resulting perhaps due to anisotropy of the sticking coefficient and mobility of adatoms. Shadowing is very prominent here and columns are elongated along a preferential growth direction. Some small regions are relatively flat as well (figure 3(d)). Figure 4 shows AFM images of $\mathrm{MgO}$ thin films synthesized by $\mathrm{MgO}$ powders obtained by burning magnesium ribbon after annealing at $500^{\circ} \mathrm{C}$ in air (group B). In figure 4(b) coarsening and agglomeration of grains with some truncated cone-like columnar growth are seen. These domeshaped grains have same size (average size, 260-370 nm and thickness, $82 \mathrm{~nm}$ ) with faintly defined boundaries. A preferential growth in a particular direction has still been 


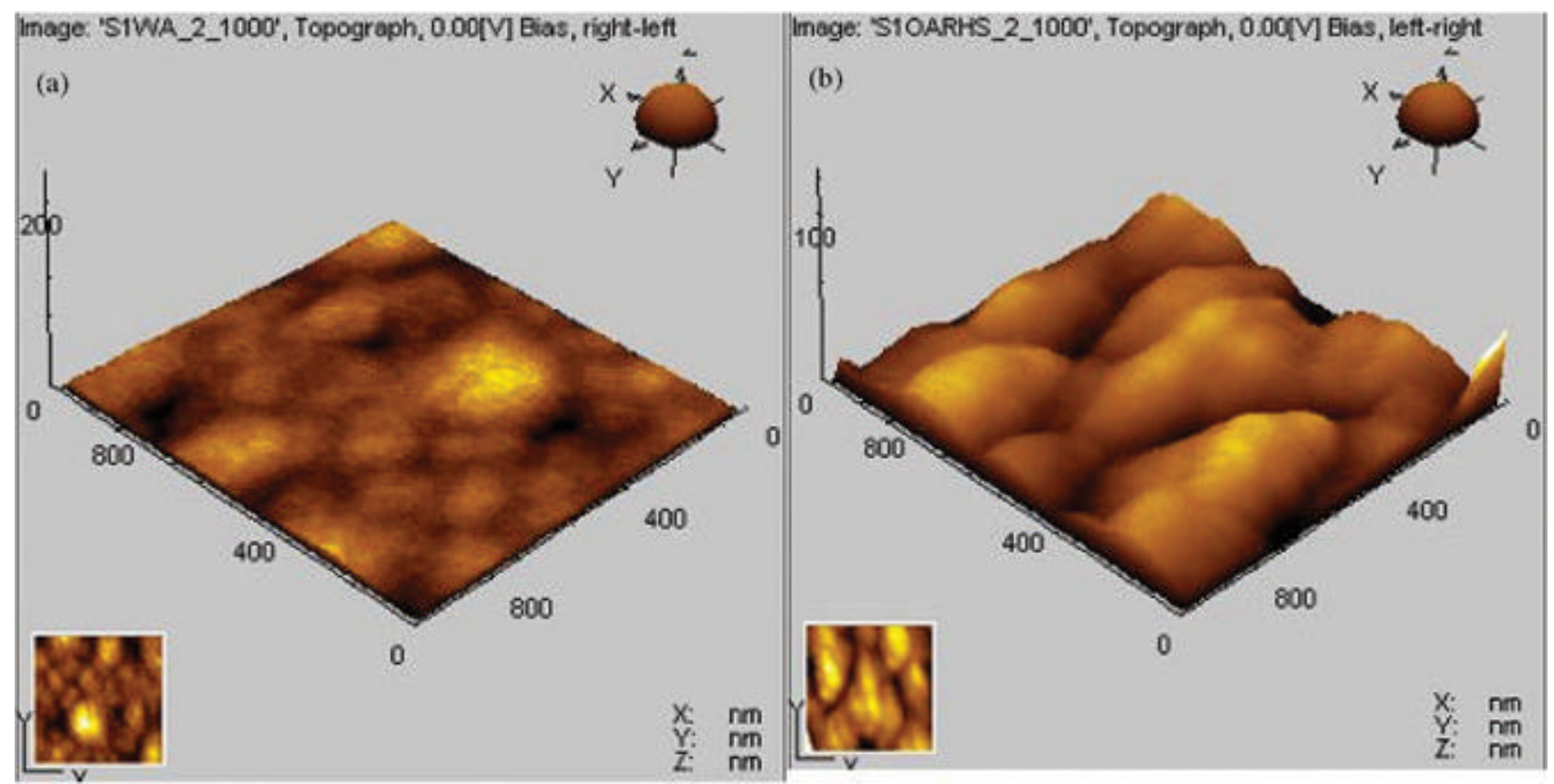

Figure 5. AFM images of e-beam evaporated $\mathrm{MgO}$ thin films synthesized by $\mathrm{MgO}$ pellet obtained by sol-gel method (a) as prepared (group F) and (b) after annealing at $500^{\circ} \mathrm{C}$ in oxygen (group D).

Table 3. RMS roughness values obtained through AFM experiment in different scan areas $(\AA)$.

\begin{tabular}{|c|c|c|c|c|}
\hline Sample code & $\mathrm{MgO}$ powder synthesis route & Processing and treatment & Scan area $\left(\mathrm{nm}^{2}\right)$ & *RMS roughness $(\AA)$ \\
\hline \multirow[t]{3}{*}{ A } & Combustion of magnesium ribbon & $\begin{array}{l}\text { Annealed at } 500^{\circ} \mathrm{C} \text { in presence of } \\
\text { oxygen with a flow rate of } 30 \mathrm{cc} / \mathrm{s}\end{array}$ & $1000 \times 1000$ & $145 \cdot 9$ \\
\hline & & & $2500 \times 2500$ & 149 \\
\hline & & & $7500 \times 7500$ & 254 \\
\hline \multirow{3}{*}{$\begin{array}{r}\text { B (region 1) } \\
\quad \text { region 2) } \\
\text { (region 3) }\end{array}$} & Combustion of magnesium ribbon & Annealed at $500^{\circ} \mathrm{C}$ in presence of air & $1000 \times 1000$ & 173.9 \\
\hline & & & $1000 \times 1000$ & $112 \cdot 9$ \\
\hline & & & $2500 \times 2500$ & 172 \\
\hline \multirow[t]{2}{*}{ D } & Sol-gel process & $\begin{array}{l}\text { Annealed at } 500^{\circ} \mathrm{C} \text { in presence of } \\
\text { oxygen with a flow rate of } 30 \mathrm{cc} / \mathrm{s}\end{array}$ & $1000 \times 1000$ & $69 \cdot 4$ \\
\hline & & & $2500 \times 2500$ & $77 \cdot 7$ \\
\hline E & Sol-gel process & Annealed at $500^{\circ} \mathrm{C}$ in presence of air & $2500 \times 2500$ & 71 \\
\hline $\mathrm{F}$ & Sol-gel process & Films as prepared (without annealed) & $1000 \times 1000$ & $17 \cdot 4$ \\
\hline
\end{tabular}

observed. Figures 4(c), (d) show island type plateau regions. The next group of AFM images (figures 5, 6) show films prepared with sol-gel derived $\mathrm{MgO}$ powder as such and after annealing at $500^{\circ} \mathrm{C}$ in oxygen (group D) and in air (group E). No preferential growth is seen in figure 6(a), but figure 5(b) shows bulging of grains assuming nearly the same height with smooth rounded surface. Figure 6(b) also shows pronounced growth of elongated shape particles with non-uniform sizes, corrugated surface and rms roughness of $\sim 69.4 \AA$. Figure 6(d) represents the annealing behaviour in air. Hence there is isolated growth of dome-shaped particles. The rms roughness values of various $\mathrm{MgO}$ films obtained from AFM observations are given in table 1.

It may be noted that group F films show less roughness values than the values reported earlier for $\mathrm{MgO}$ (Menon and Bullard 1999; Kim et al 2000, 2004; Jung et al 2002), whereas the other films (groups D and E) correspond to a reasonably good degree of smoothness (roughness, < $80 \AA$ ).

So, it can be inferred that the oxygen annealed films are more transparent than air annealed ones due to less roughness and hence more uniformity. A comparison between films prepared by sol-gel process and by combust- 

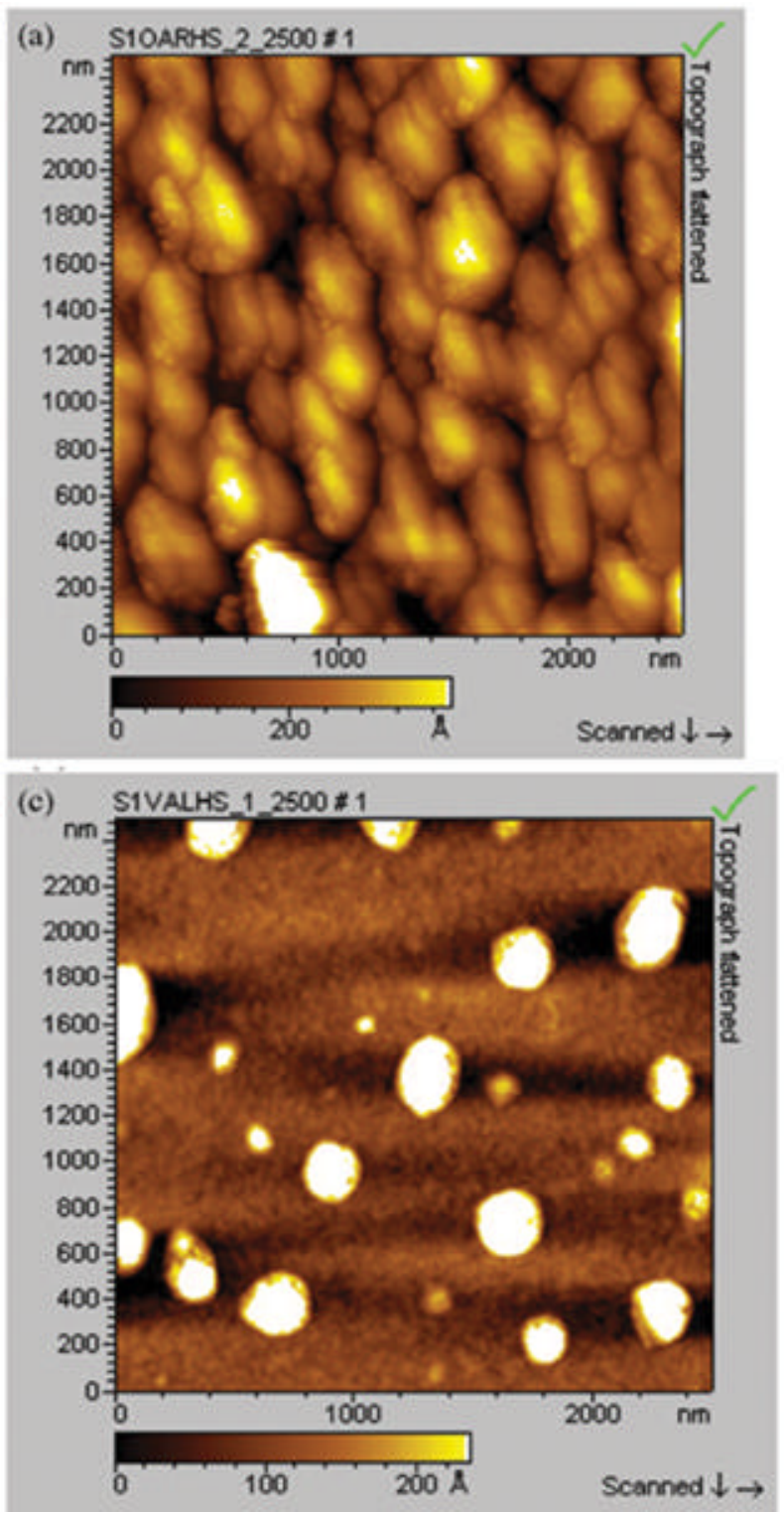
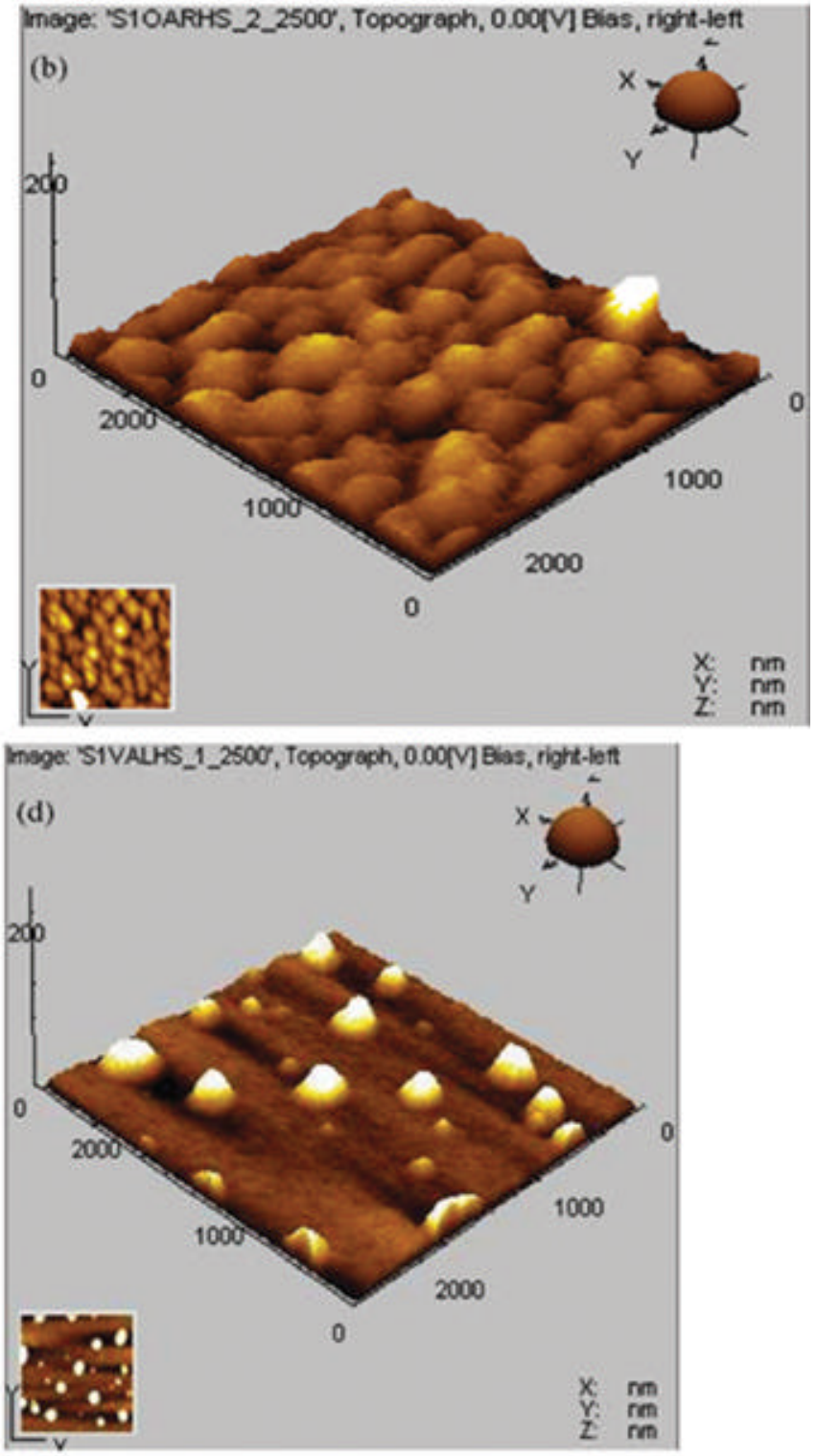

Figure 6. AFM images of e-beam evaporated $\mathrm{MgO}$ thin films synthesized by $\mathrm{MgO}$ pellet obtained by sol-gel method after annealing at $500^{\circ} \mathrm{C}(\mathbf{a}, \mathbf{b})$ in oxygen (group D) and (c, d) in air (group E).

ion of ribbon shows the former one to be more transparent. This inference is consistent with UV spectroscopy transmittance data described possibly due to finer grain size. In conclusion, the film growth mode appears to be of 3D Stranski-Krastanov type (layer plus island growth) for $\mathrm{MgO}$.

The RMS roughness values given here in table 3 are reported after subtracting the roughness values for glass substrate, which is found as $7 \cdot 1 \AA$ and $11 \AA$, respectively for an area of $1000 \times 1000$ and $2500 \times 2500 \mathrm{~nm}^{2}$, respectively.

The transmission (\%) vs wavelength plots of different thin film samples deposited on glass substrates are shown in figure 7. The nature in the plots is the same with transmission at nearly $90 \%$ for all except group C sample (where \% $T \sim 78$ ) in the wavelength range 350-800 $\mathrm{nm}$. The results clearly demonstrate that annealing improves the transparency for thin films produced with $\mathrm{MgO}$ powder obtained by combustion of magnesium ribbon. Also sol-gel derived $\mathrm{MgO}$ powder thin film invariably shows high transmission due to the annealing process. There is a dip invariably present at slightly after $350 \mathrm{~nm}$, the transmission decreases sharply indicating strong absorption of the radiation.

\section{Conclusions}

The SEM images discover a very unique self-assembled kind of a structure which has been assigned to the formation of $\mathrm{Mg}(\mathrm{OH})_{2}$, however, the propagation route of the network 


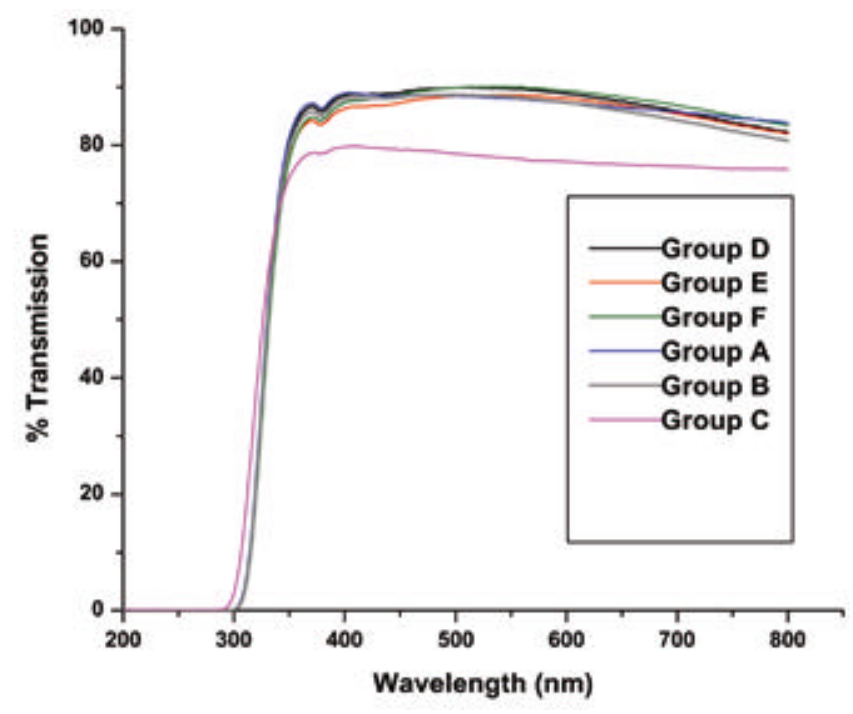

Figure 7. Transmission vs wavelength plots of e-beam evaporated $\mathrm{MgO}$ thin films. $\mathrm{MgO}$ thin films prepared by $\mathrm{MgO}$ powder/ pellet from combustion of magnesium ribbon without annealed (group C), air annealed (group B) and annealed in oxygen (group A) and sol-gel process without annealed (group F), air annealed (group E) and annealed in oxygen (group D).

cannot be specified at this stage. This study shows that hydration does not depend on the post treatments on the film e.g. annealing as both groups $\mathrm{C}$ and $\mathrm{D}$ films are affected by this. The structures of the mesh formed are also different in these two films.

AFM studies have been carried out and after comparison of the microstructure of different films, it can be said that, the results obtained here are quite different from what have been observed in case of structure-zone model for evaporated films (mostly done for metals). The growth of the films is only observed after annealing with oxygen annealing providing support for pronounced columnar growth. The columns of different shapes have also been observed. Air annealing is shown to produce truncated columns. However, a much in-depth analysis is needed to have a final say on this issue.

\section{Acknowledgements}

The authors are grateful to Mr Mohit Lakhera, Vac. Tech. Engineers, for his help and support in the preparation of thin films. We also extend our sincere thanks to $\mathrm{Mr}$ Dinesh Deva in doing the AFM experiment.

\section{References}

Boeuf J P 2003 J. Phys. D Appl. Phys. 36 R53

Boo J H, Yu K S, Koh W and Kim Y 1996 Mater. Lett. 26233

Chakrabarti S, Ganguli D, Chaudhuri S and Pal A K 2002 Mater. Lett. 54120

Chakrabarti S, Ganguli D and Chaudhuri S 2003 Mater. Lett. 57 4483

Chowdhury A 2005 Synthesis and characterization of magnesium oxide powder and electron beam evaporated thin films, M.Tech. Thesis, IIT Kanpur

Ho I C, Xu Y and Mackenzie J D 1997 J. Sol-Gel Sci. Technol. 9295

Huang Ron and Kitai Adrian H 1992 Appl. Phys. Lett. 611450

Imai F et al 1992 Appl. Surf. Sci. 60-61 770

Jung Hyun Suk, Lee Jung-Kun, Hong Kug Sun and Youn HyukJoon 2002 J. Appl. Phys. 922855

Kim B I, Hung J W, Jeung G T, Moon S H, Lee D H, Shin T U and Khim Z G 1994 J. Vac. Sci. Technol. B12 1631

Kim Jong-Kuk, Lee Eun-Sung, Kim Dong-Ho and Kim Do-Geun 2004 Thin Solid Films 447-448 95

Kim R, Kim Y, Cho J and Park J W 2000 J. Vac. Sci. Technol. A18 2493

Menon M and Bullard J W 1999 Mater. Chem. 9949

Milton Ohring 2001 The materials science of thin films (New York: Academic Press) Ch. 9

Nashimoto K, Fork D K and Geballa T H 1992 Appl. Phys. Lett. 601199

Park Chung-Hoo, Kim Young-Kee, Lee Sung-Hyun, Lee WooGeun and Sung Youl-Moon 2000 Thin Solid Films 36688

Phillipsa Julia M 1996 J. Appl. Phys. 791829 